Original Paper

\title{
Characterization of Inorganic Constituents in Oil Palm (Elaeis guineesis) by SEM-EDXA
}

\author{
Yosuke Tono, Hisashi MiYafuJI, Masashi ShiBATA, and Shiro SAKA \\ (Received March 12, 2007)
}

\author{
SEM-EDXA 法によるアブラヤシの無機成分分析 \\ 東野陽介，宮藤久士，芝田正志，坂 志朗
}

\begin{abstract}
Studied were inorganic constituents of the ash from various parts of oil palm (Elaeis guineensis) such as trunk, frond, mesocarp, endocarp (shell), kernel cake and empty fruit bunch (EFB) by scanning electron microscopy equipped with energy-dispersive X-ray analysis (SEM-EDXA). As a result, K, Si, Na, Ca, S, P and $\mathrm{Mg}$ were found as elements in all parts of the oil palm studied. Particularly, Si and K were abundant in the trunk, shell, mesocarp and kernel cake, while the frond and kernel cake contained, respectively, K, Ca and P in a large quantity. The elements of $\mathrm{Cl}, \mathrm{Fe}$ and $\mathrm{Al}$ were, however, detected only in some parts.

There existed three types of shapes in the ash such as needle, sphere and fluffy substances in the oil palm. However, the needles were found only in the trunk with spheres. In some other parts such as frond, shell, kernel cake and EFB, fluffy and sphere substances were found in their ash, while in the mesocarp, only fluffy substances were observed. For the needles and spheres, elements of $\mathrm{Na}$ and $\mathrm{Si}$ were, respectively, found to be localized, whereas fluffy substances contained all of the elements such as K, Si, Na, Ca, S, P and $\mathrm{Mg}$ with sometime $\mathrm{Cl}$, Fe and $\mathrm{Al}$.

These elements found are important and prerequisite for the healthy growth of the oil palm. Therefore, it may be concluded that, upon the whole utilization of the oil palm, inorganic constituents found in this study must be returned to the plantation site. Otherwise, the same has to be compensated to its site for sustainable development.
\end{abstract}

Key Words

Oil palm, Trunk, Frond, Mesocarp, Endocarp, Shell, Kernel Cake, EFB, Ash, SEM-EDXA

\section{1. 緒 言}

化石資源の消費により排出される二酸化炭素の温室効果が 主原因とされる温暖化は，地球規模でのエネルギー・環境問 題としてその解決が急務となっている。一方, 大気中の二酸 化炭素と水を用いた光合成によって生合成されるバイオマス は，地球温暖化の抑制に寄与する環境負荷の小さい資源とし て，その利用に期待が寄せられている。中でも各種油脂資源 から調製されるバイオディーゼルは自動車等の燃料として注 目を集めており，すでに世界各地で実用化の段階にある。 バイオディーゼルの製造には様々な油脂原料が利用できる が，アブラヤシから得られるパーム油 (Palm Oil) やパーム核 油 (Palm Kernel Oil) もその原料として有望視されており，マ

Graduate School of Energy Science, Kyoto University

Yoshida-honmachi, Sakyo-ku, Kyoto 606-8501, Japan
レーシア，インドネシアなどの東南アジアで, 大規模なプラ ンテーションが行われている。しかしながら，パーム油やパー ム核油はアブラヤシの生鮮果房 (FFB：Fresh Fruit Bunch)の 果実部から得られ，油糧成分の抽出過程に拈いて，空果房 (EFB : Empty Fruit Bunch), 中果皮 (Mesocarp), 内果皮 (Endocarp (Shell)), パーム核粕 (Kernel Cake) などの様々な 廃バイオマスを生じる。さらに，プランテーション地におい ては, 茎葉 (Frond) や伐採時に生じる幹 (Trunk) なども未 利用のまま放置され，廃バイオマスとなっている。

これらのマレーシアにおける年間発生量は, EFBが 1,340 万

t, Mesocarp が 700 万t, Shell が 410 万t, Kernel Cake が 190 万t, Frondが 110 万t, Trunkが500万 t と報告されている1)。

京都大学大学院エネルギー科学研究科

干 606-8501 京都府京都市左京区吉田本町 
一部は肥料や飼料，あるいは工場のボイラー用燃料として利 用されてはいるものの, ほとんどが未利用のまま廃棄されて いるのが現状である。したがって，パーム油やパーム核油の みならず，これらの廃バイオマスについても資源として活用 し，アブラヤシの総合的有効利用を図ることが重要で, バイ オマスの利用促進，廃衰物の低減といった観点から大変意義 深いことである。

そこで，まずアブラヤシ各部位の化学成分組成をはじめと する基礎的なデー夕2) を得るとともに，本論文では，エネル ギー分散型 X 線分析装置を装備した走査型電子顕微鏡（SEM -EDXA ${ }^{3)}{ }^{4)}$ を用いてアブラヤシ中の無機成分について分析 を行い，アブラヤシに存在する無機元素の基礎的な知見を得 ることを目的とした。なお，この無機成分に対しては，コン クリート原料としての利用 5) 6) や大気・水質污染物質の吸着 剂7) -9) としての応用的研究がなされているが, 本研究で見ら れる基礎的な研究はほとんどなされていない。

\section{2. 実 験}

\section{1 試 料}

試料として，マレーシア産アブラヤシ（Elaeis guineensis Jacq.)を用いた。幹(Trunk), 茎葉 (Frond), 中果皮(Mesocarp), 内果皮 (Endocarp)（本研究では, 材料としての利用を検討す るため, Endocarpの代わりに，以後Shell（果実殼）と表記す る)，核 (Kernel) (本研究では, Kernel からパーム核油を搾 り出した残渣を用いるため，Kernel の代わりに，以後Kernel Cake (パーム核粕) と表記する) および空果房（EFB：Empty Fruit Bunch）に当たる6 部位を取り出した。これらをWiley 型粉砕機（1029-C，吉田製作所製）を用いて $\phi 0.5 \mathrm{~mm}$ 以下に 粉砕し, エタノール：ベンゼン（1:2（v/v)）（共に, ナカ ライテスク製，特級）混合溶媒により 8 時間のソックスレー 抽出を行い，実験に供した。

\section{2 灰分の調製}

約 $1.0 \mathrm{~g}$ の絶乾試料をるつぼに入れ，これをマッフル炉にて $600^{\circ} \mathrm{C}$ で 2 時間加熱処理を行うことで灰分を得た。この時のる つぼ内の残渣重量を灰分量とし，加熱処理前の無抽出試料の 絶乾重量をもとに灰分含量（wt\%）を算出した。

\section{3 走査型電子顕微鏡一エネルギー分散型 X線分析（SEM - EDXA 分析)}

試料台に貼り付けたカーボンテープの上に死分試料を分散 させ，蒸着処理を行うことなく，エネルギー分散型 X線分析 装置（EDAX社製 Phoenix）を装備した走査型電子顕微鏡（日 本電子製 JSM - 5800）を用い，加速電圧 $20 \mathrm{kV}$ にて SEM EDXA分析を行った。特性X線のマッピングについては, Na$\mathrm{K} \alpha \mathrm{X}$ 線（0.99keV-1.08keV）および $\mathrm{Si}-\mathrm{K} \alpha \mathrm{X}$ 線（1.68keV$1.79 \mathrm{keV})$ を用いた。

\section{3. 結果および考察}

3.1 灰 分

Table 1に, 各試料の灰分含量を示す。Shellにおける1.0wt \%から Mesocarp における 9.3wt\%まで，アブラヤシの部位に よって灰分含量が大きく異なることが分かる。また，灰分の 色も Fig. 1 に示すように, Trunk, Kernel Cake, EFB では茶 褐色であるのに対し, Frondは白色, Shellは黒褐色, Mesocarp は赤褐色と様々であり，灰分を構成する元素の種類や組成が 部位により異なることが示唆される。そこで, 各試料中に含 まれる元素を明らかにするためエネルギー分散型 X 線分析を 行った。

\subsection{SEM - EDXA 分析}

\subsection{1 幹 (Trunk)}

Fig. 2 には, Trunk から得られた扊分の SEM - EDXA 分析 の結果を示す。(a)のSEM写真より，浮遊状物（Fluffy；だ円 内), 針状 (Needle; 長方形内), 球状 (Sphere; 円内) の形状 の異なるものが含まれていることが分かる。

これらの物質を光学顕微鏡で観察したところ，偏向顕微鏡 のクロスニコルのもと針状物は複屈折を示すことより, 結晶 体であること, 一方球状物や浮遊状物は複屈折を示さず，非 晶であることを確認した。佐伯ら ${ }^{10)}$ の研究からも, 針状のも のは結晶体であると考えられる。

さて，Fig. 2(b)には，(a)の視野におけるEDXAスペクトル を示しており， $\mathrm{Na}, \mathrm{Mg}, \mathrm{Al}, \mathrm{Si}, \mathrm{P}, \mathrm{S}, \mathrm{Cl}, \mathrm{K}$ およびCaが含 まれていることが分かる。また，(c)には（a）の視野における $\mathrm{Na}-\mathrm{K} \alpha \mathrm{X}$ 線のマッピングを示しているが，球状物以外の部分 でNaが存在していることが分かる。(d)には，針状結晶での

Table 1 Yield of the ash from various parts of the oil palm

\begin{tabular}{lc}
\hline Part & Ash content (wt\%) \\
\hline Trunk & 4.1 \\
Frond & 5.7 \\
Mesocarp & 9.3 \\
Shell & 1.0 \\
Kernel Cake & 6.7 \\
EFB & 1.5 \\
\hline
\end{tabular}

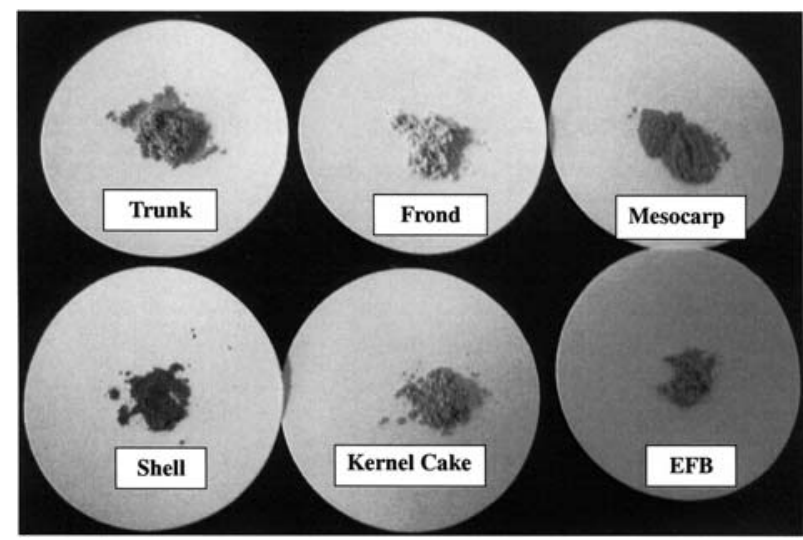

Fig. 1 The ash from 6 different parts of the oil palm 

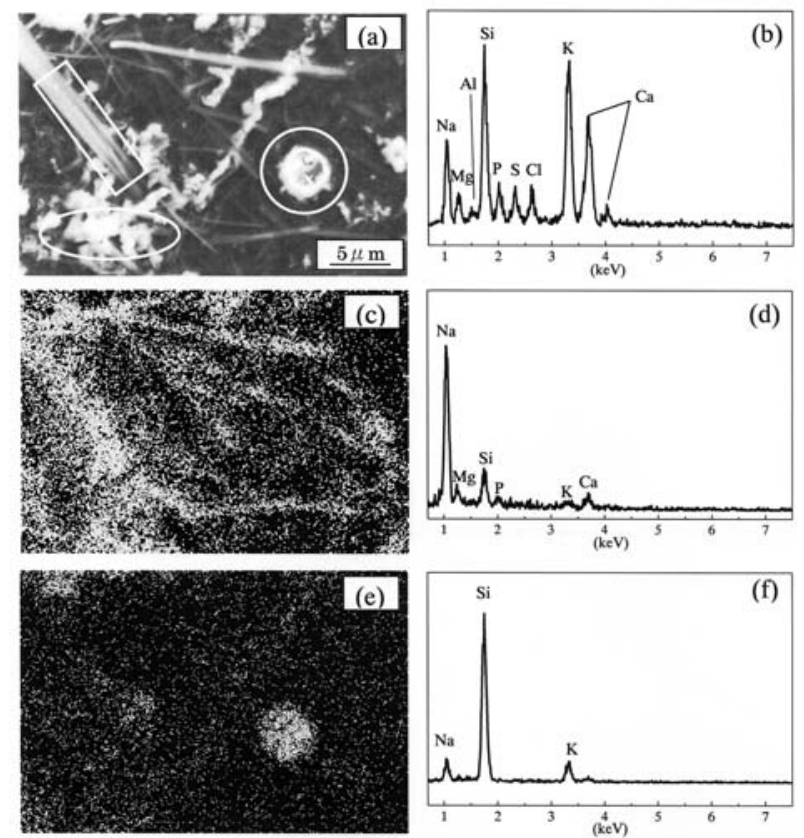

Fig. 2 SEM - EDXA on ash from the Trunk

(a) Scanning electron micrograph

(b) EDXA spectrum for (a)

(c) Distribution map of $\mathrm{Na}-\mathrm{K} \alpha \mathrm{X}$-rays for (a)

(d) EDXA spectrum for needle crystals

(e) Distribution map of Si-K $\alpha$ X-rays for (a)

(f) EDXA spectrum for sphere substances

EDXA分析の結果を示しており，特徵的な元素としてNaの強 いピークが確認され，Naが針状結晶に局在しているものと考 えられる。一方 (e)には，(a)の視野での $\mathrm{Si}-\mathrm{K} \alpha \mathrm{X}$ 線のマッピ ングを，(f)には，球状物でのEDXA分析の結果を示している。 これらの結果より，球状物にはSiが局在しているものと考え られる。

\subsection{2 茎葉 (Frond)}

Fig. 3 には, Frond から得た灰分の SEM - EDXA 分析の結 果を示す。(a)のSEM 写真より，浮遊状物と球状物が灰分に 含まれていることが分かる。(b)には，(a)の視野における EDXAスペクトルを示しており， $\mathrm{Na}, \mathrm{Mg}, \mathrm{Si}, \mathrm{P}, \mathrm{S}, \mathrm{Cl}, \mathrm{K}$ お よびCaの元素を含んでいることがわかる。また，(c)には (a) の視野での $\mathrm{Si}-\mathrm{K} \alpha$ マッピングを示しており, 球状物に主とし てSiが集中していることが分かる。さらに，(d)のスペクトル は球状物からのものであるが, 特徵的な $\mathrm{Si}-\mathrm{K} \alpha \mathrm{X}$ 線の強いピー クが確認できる。これらの結果から, Trunkでの場合と同様, $\mathrm{Si}$ が球状物に局在していることがわかる。

\subsection{3 中果皮 (Mesocarp)}

Fig. 4 には, Mesocarpから得た灰分のSEM - EDXA 分析の 結果を示す。(a)の SEM 写真から，浮遊状物と球状物の形態 が観察される。また，（b）に示すように, EDXA 分析からは, $\mathrm{Na}, \mathrm{Mg}, \mathrm{Al}, \mathrm{Si}, \mathrm{P}, \mathrm{S} ， \mathrm{~K}$ ，CałよびFeなど多くの元素が検 出されている。(c)に示しているSi-K $\alpha$ X線マッピングおよび (d)に示している球状物からのEDXAスペクトルの結果から,
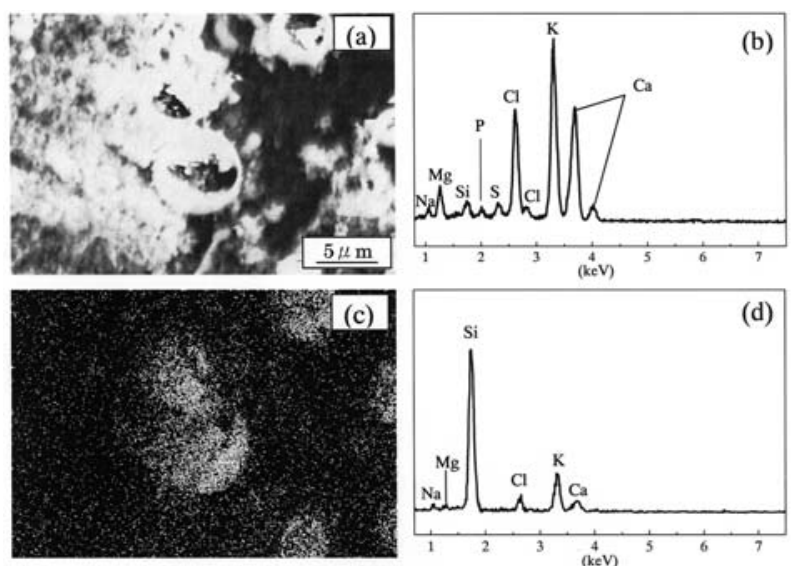

Fig. 3 SEM - EDXA on ash from the Frond

(a) Scanning electron micrograph

(b) EDXA spectrum for (a)

(c) Distribution map of Si-K $\alpha$ X-rays for (a)

(d) EDXA spectrum for sphere substances
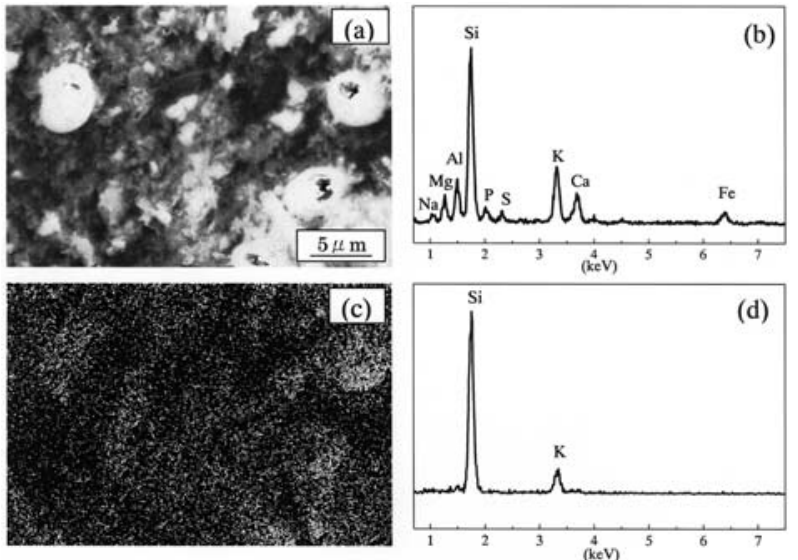

Fig. 4 SEM - EDXA on ash from the Mesocarp

(a) Scanning electron micrograph

(b) EDXA spectrum for (a)

(c) Distribution map of Si-K $\alpha$ X-rays for (a)

(d) EDXA spectrum for sphere substances

これまでの他の部位での結果と同様，Si が球状物に局在して いることが確認される。

\subsection{4 果実殼（Shell）}

Fig. 5 には, Shell から得た灰分のSEM - EDXA 分析の結果 を示す。Trunk および Frond と同様, 浮遊状物と球状物が兏 分中に含まれている。また，(b)に示す (a)の視野からのEDXA スペクトルより， Na， Mg， Al, Si，P，S，K，CaおよびFeな ど多くの元素が含まれていることが分かる。しかし，ここで は，TrunkやFrond では見られなかった鉄（Fe）が微量含ま れている。(c)には, 球状物に対する $\mathrm{Si}-\mathrm{K} \alpha \mathrm{X}$ 線のマッピン グを，(d)には球状物に対するEDXAスペクトルを示している が，球状物には，Si が局在化していることが分かる。

\subsection{5 パーム核粕（Kernel Cake）}

Fig. 6 には, Kernel Cakeから得られた灰分のSEM-EDXA 分析の結果を示す。Kernel Cakeでは，(a)のSEM写真に示す 

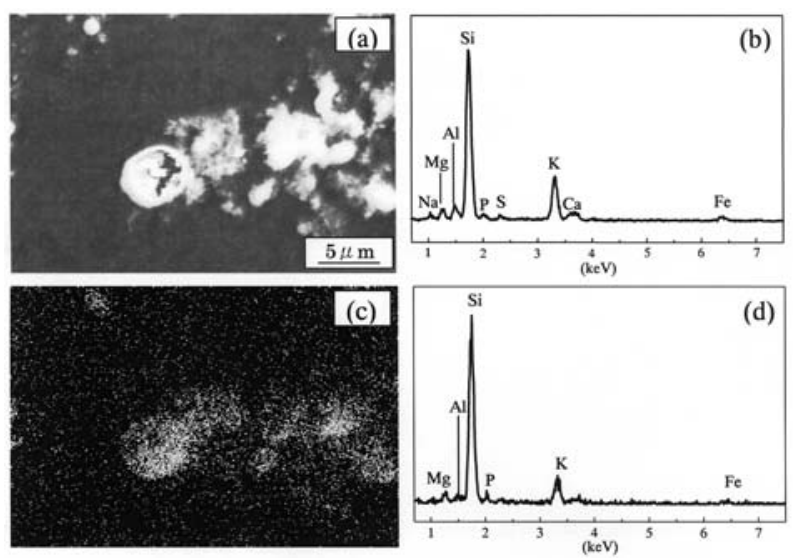

Fig. 5 SEM - EDXA on ash from the Shell

(a) Scanning electron micrograph

(b) EDXA spectrum for (a)

(c) Distribution map of Si-K $\alpha$ X-rays for (a)

(d) EDXA spectrum for sphere substances
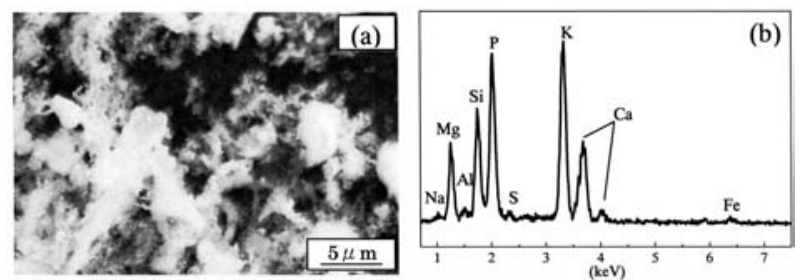

Fig. 6 SEM - EDXA on ash from the Kernel Cake

(a) Scanning electron micrograph

(b) EDXA spectrum for fluffy substances

ように, 浮遊状物のみが観察され，針状結晶や球状物は観察 されなかった。また，(b)に示すようにEDXA分析からは，Na， $\mathrm{Mg}, \mathrm{Al}, \mathrm{Si}, \mathrm{P}, \mathrm{S}, \mathrm{K}, \mathrm{Ca}$ 㧍よび Fe の存在が確認される。
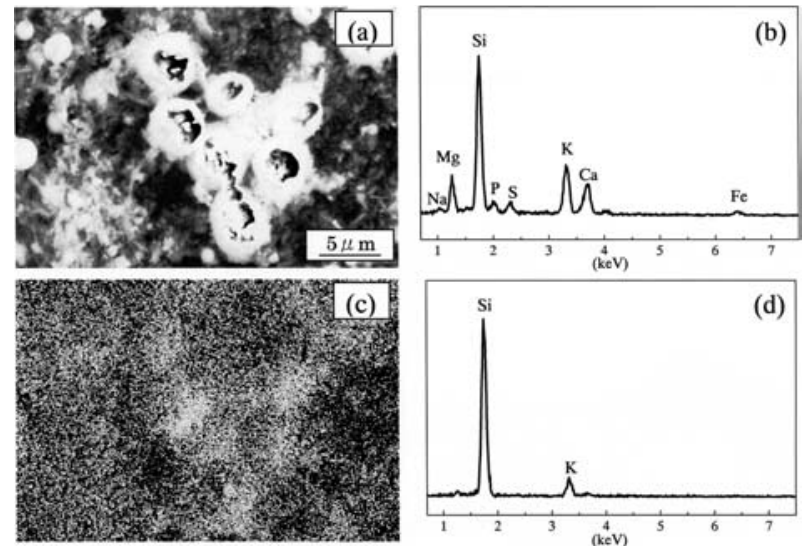

Fig. 7 SEM - EDXA on ash from the EFB

(a) Scanning electron micrograph

(b) EDXA spectrum for (a)

(c) Distribution map of Si-K $\alpha$ X-rays for (a)

(d) EDXA spectrum for sphere substances

\subsection{6 空果房 (EFB)}

Fig. 7 には, EFBから得られた扊分の SEM - EDXA 分析の 結果を示す。ここでもKernel Cake以外の部位と同様, 浮遊状 物と球状物が観察された。また，(b)に示すように, EDXA分 析からは $\mathrm{Na}, \mathrm{Mg}, \mathrm{Si}, \mathrm{P}, \mathrm{S}, \mathrm{K}, \mathrm{Ca}$ および Fe など多くの元 素が検出された。(c)の $\mathrm{Si}-\mathrm{K} \alpha \mathrm{X}$ 線のマッピングや，(d)に示 す球状物からの EDXA スペクトルで $\mathrm{Si}-\mathrm{K} \alpha \mathrm{X}$ 線の強いピーク が見られたことから，これまでの他の部位での結果と同様， $\mathrm{Si}$ が球状物に局在していることが明らかである。

\section{3 構成元素の比較}

以上の結果から，アブラヤシの各部位から得た扊分を構成

Table 2 Inorganic constitutes in ash from various parts of oil palm

\begin{tabular}{|c|c|c|c|c|c|c|c|c|c|c|c|}
\hline \multirow[t]{2}{*}{ Parts } & \multirow[t]{2}{*}{ Shapes } & \multicolumn{10}{|c|}{ Elements } \\
\hline & & $\mathrm{K}$ & $\mathrm{Si}$ & $\mathrm{Na}$ & $\mathrm{Ca}$ & $\mathrm{Cl}$ & $\mathrm{S}$ & $\mathrm{P}$ & $\mathrm{Mg}$ & $\mathrm{Fe}$ & $\mathrm{Al}$ \\
\hline \multirow[t]{3}{*}{ Trunk } & Needle & + & ++ & +++ & + & & & + & + & & \\
\hline & Fluffy & ++ & +++ & + & + & + & + & + & + & & + \\
\hline & Sphere & + & +++ & ++ & & & & & & & \\
\hline \multirow[t]{3}{*}{ Frond } & Fluffy & +++ & + & + & ++ & + & + & + & + & & \\
\hline & Sphere & ++ & +++ & + & + & + & & & & & \\
\hline & & & & & & + & & & & & \\
\hline \multirow[t]{2}{*}{ Mesocarp } & Fluffy & ++ & +++ & + & + & & + & + & + & + & + \\
\hline & Sphere & ++ & +++ & & & & & & & & \\
\hline \multirow[t]{2}{*}{ Shell } & Fluffy & ++ & +++ & + & + & & + & + & + & + & + \\
\hline & Sphere & ++ & +++ & & & & & & + & + & \\
\hline Kernel Cake & Fluffy & +++ & + & + & + & & + & ++ & + & + & + \\
\hline \multirow[t]{2}{*}{$\mathrm{EFB}$} & Fluffy & ++ & +++ & + & + & & + & + & + & + & \\
\hline & Sphere & ++ & +++ & & & & & & & & \\
\hline
\end{tabular}

+++ : Extremely abundant

++ : Abundant

$+\quad$ : Existing 
する針状結晶と非晶の浮遊状物や球状物の構成元素をTable 2 にまとめた。ここで，それぞれのEDXA分析における特性X 線の強度の程度を高いものから,,++++++ と表記して いる。Trunkで針状結晶および球状物の 2 形態が見られたが, Kernel Cakeでは非晶の浮遊状物のみであり，その他の部位で は，浮遊状物と共に球状物が圧分中に含まれている。なお，球 状物や針状結晶にはそれぞれ $\mathrm{Si}$ および $\mathrm{Na}$ が局在し，浮遊状 物にはKまたは/およびSiが局在し，そのほかの元素 $\mathrm{Na}, \mathrm{Ca}$, $\mathrm{S}, \mathrm{P}$ および $\mathrm{Mg}$ が微量ながら常に存在している。さらに部位 によっては， $\mathrm{Cl} ， \mathrm{Fe}$ および $\mathrm{Al}$ が見出された。

構成元素については，いずれの部位でも K, Si， Na， Ca， S, PおよびMgが存在し，つねに 8 元素が見い出される。し かし，Cl は Trunk およびFrondに, Fe は Shell, Mesocarp, Kernel Cake およびEFBに, Al は Trunk, Mesocarp, Shell お よびKernel Cakeにのみ存在しており，部位によって存在する 元素の種類が異なることが明らかである。また，最も量の多 かった元素 2 種を比較すると, Trunk, Mesocarp, Shell, EFB では，SiおよびKであるが，Frondでは，KおよびCaであり， Kernel Cakeでは，K およびPである。

このように，アブラヤシでは，部位によって含まれる元素 の種類や量が大きく異なることが明らかである。そこで種々 のバイオマス資源の灰分との比較を以下に行ってみる。

アブラヤシは被子植物の単子葉類に分類される多年生植物 であるが，被子植物の多年生植物で双子葉類であるシラカン バ (広葉樹) 4) あるいは裸子植物の一種であるブラックスプ ルース (針葉樹) ${ }^{3)}$ といった木材では，灰分含量は $0.5 \mathrm{wt} \%$ 以 下でありアブラヤシに比べ非常に低く，主要な元素としてCa， $\mathrm{K}, \mathrm{Mg}$ が含まれていることが報告されている。

一方，単子葉植物の一年生植物である稲わら ${ }^{11)}$ ，麦わら ${ }^{12)}$ では灰分含量はそれぞれ 7.6wt\%，9.8wt\%と高く，構成元素 は Si と K が多く含まれていることが報告されている。また， 籾殼 ${ }^{13)}$ についても同様に Si と K が主要構成成分であるとの

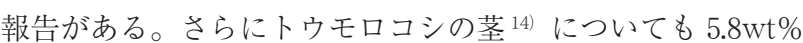
の灰分が含まれ，Siが最も高く，次いで $\mathrm{Mg}, \mathrm{Ca}, \mathrm{K}$ の順に存 在することが明らかとなっている。

これらの結果から，アブラヤシがいずれの部位においても 多量の灰分を含有し, Frond, Kernel Cakeでは異なるものの, Trunk, Mesocarp, Shell, EFBにおいて Si およびKが主要な 元素であるという本研究結果は, 単子葉類に共通する特徵的 なものであるとも捉えられるが，生育地の土壤などの影響も 無視できない因子の一つであると考えられる。

\section{4. 結 言}

本研究で明らかとなったアブラヤシ灰分を構成する元素は, 生体の生命活動に必須な元素を多く含んでいる。したがって, 現状，Frond や Trunk はプランテーション地に未利用のまま 放置させているが，これらの部位に含まれる元素を土䁃へ還 元する意味では有効である。

しかしながら，生鮮果房 (FFB) は，果実からの油糧の採取 のため林地から工場へと搬出され，その結果，含有するすべ ての無機元素が林地から持ち出されたことになる。搾油後，分
離された Mesocarp, Shell, Kernel Cake および EFBは，必要 に応じて工場のボイラーの熱源, 活性炭原料, 家畜の飼料と して利用されている。また，これらをプランテーション地に 還元する場合もあるが15)，有効利用されずに廃棄されている 場合が多い。

このような状況の下，アブラヤシの種々の部位が有効に利 用される総体利用が強く望まれるが，一方で持続可能なアブ ラヤシのプランテーションを可能にするためには, 持ち出さ れた無機成分の林地への還元を考慮した有効利用が重要とな る。その際に本研究の成果が役立つことを願っている。

\section{謝 辞}

本研究で用いた試料は，マレーシア工科大学の Farid Nasir Bin Hj Ani 教授, マレーシア科学大学の Wan Rosli Wan Daud 教授および Ir Mohd Omar Ab Kadir 教授より供与いただいた ものであり，ここに御礼申し上げる。

\section{文 献：References}

1) 坂志朗，バイオディーゼルのすべて,(アイピーシー), p.9 (2006) : Saka, S., All about Biodiesel, (IPC Publisher), p.9 (2006)

2）芝田正志, マヘンドラ バーマン, 東野陽介, 宮藤久士, 坂志 朗, 日エネ誌(投稿中)：Shibata, M., Varman, M., Tono, Y., Miyafuji, H., Saka, S., J. Jpn. Inst. Energy (Submitted)

3) Saka, S., Goring, D. A. I., Mokuzai Gakkaishi, 29, 648(1983)

4) Saka, S., Mimori, R., Mokuzai Gakkaishi, 40, 88(1994)

5) Sata, V., Jaturapitakkul, C., Kiattikomol, K., J. Materials in Civil Engineering., 16, 623(2004)

6) Tangchirapat, W., Saeting, T., Jaturapitakkul, C., Kiattikomol, K., Siripanichgorn, A., Waste Management, 27, 81 (2007)

7) Chu, K. H., Hashim, M. A., J. Chem. Technol. Biotechnol., 77, 685 (2002)

8) Zainudin, N. F., Lee, K. T., Kamaruddin, A. H., Bhatia, S., Mohamed, A. R., Separation and Purification Technology, 45, 50 (2005)

9) Mohamed, A. R., Lee, K. T., Noor N. M., Zainudin, N. F., Chem. Eng. Technol., 28, 939 (2005)

10）佐伯浩，走査電子顕微鏡図説, (日本林業技術協会), p.196198(1982) : Saiki, H.,Sosa-denshi-kenbikyo Zusetsu (Nihon Ringyo Gijyutsu Kyokai), p.196-198(1982)

11) Lang, T., Jensen, P. A., Knudsen, J. N., Energy \& Fuels, 20, 796 (2006)

12) Thy, P., Jenkins, B. M., Grundvig, S., Shiraki, R., Lesher, C. E., Fuel, 85, 783(2006)

13) Siriwardena, S., Ismail, H., Ishiaku, U. S., Polym.Int., 50, 707 (2001)

14) Arvelakis, S., Folkedahl, B., Dam-Johansen, K., Hurley, J., Energy \& Fuels, 20, 1329(2006)

15）田中良平，小杉昭彦，森隆，日エネ誌，86(6)，368 (2007) : Tanaka, R., Kosugi, A., Mori, Y., J. Jpn. Inst. Energy, 86(6), 368(2007) 